\title{
Water, Sanitation and Hygiene Condition in Public Schools from Ten Districts of Lumbini, Karnali and Sudurpaschim Province, Nepal
}

\author{
Mr. Anjan Kumar Phoju ${ }^{*}$, Mr. Prakash Koirala ${ }^{2}$, Ms. Sharmila Bajracharya ${ }^{3}$ \\ ${ }^{1}$ Sr. Program/MEAL/Climate Change Officer, Integrated Development Society-Nepal \\ ${ }^{2}$ Executive Director, Integrated Development Society-Nepal \\ ${ }^{3}$ E\&S Analyst, Dolma Advisors Pvt. Ltd
} *Corresponding Authors: Mr. Anjan Kumar Phoju, Sr. Program/MEAL/Climate Change Officer,
Integrated Development Society-Nepal

\begin{abstract}
This paper is based on research conducted in 3,534 public schools in Nepal's Lumbini, Karnali, and Sudurpaschim province. The information was gathered from public schools, both SMP and non-SMP. Questionnaires were used to collect the majority of the data. Increased access to WASH (water, sanitation, and hygiene) in schools increases student health and efficiency. WASH services in schools are being scaled up around the world, but little is known about the state of public schools in Nepal. The survey was conducted in 10 districts in three provinces, with 3,534 public schools. As envisioned by School WASH Operational Procedure, 2074, the WASH profile outlined a range of areas where priority and attention are needed for improvement. Since everyday practices in schools are open to person-to-person interaction, schools with inadequate water, sanitation, and hygiene (WASH) conditions have a higher risk of illness and disease, as well as increased infection. In schools, providing proper water, sanitation, hygiene, and waste disposal has a range of benefits. This study reveals that public schools in rural areas need significant change and must encourage hardware components. Owing to a shortage of clean water and toilets in the classrooms, students do not wash their hands often. Secondary students also have poor hand washing habits and low self-esteem when it comes to maintaining hygiene and sanitation. Unsafe WASH conditions will impede students physical and cognitive abilities. Waterborne communicable diseases can be reduced by taking simple steps to foster healthy behaviors, such as proper hand washing practices and a safe school environment. This survey is helpful in establishing the baseline status of the selected districts for potential WASH sector progress review.
\end{abstract}

Key Words: Schools, Students, Water, Sanitation, Hygiene, Practices, hand washing

\section{INTRODUCTION}

Diseases caused by a lack of clean water, sanitation, and hygiene are a major burden in developing countries. About 1.2 billion people in the world do not have access to healthy drinking water, and another 2.6 billion do not have access to adequate and convenient sanitation. According to the World Health Organization (WHO, 2004), 1.8 million people die each year from diarrhea and cholera, which are linked to a lack of clean drinking water and basic sanitation facilities. WASH (Water, Sanitation, and Hygiene) are some of the most important requirements for human health and the ability to live a normal life. Access to clean water is vital for people's health, protection, livelihood, and quality of life, and it is particularly important for women and girls because they are the ones who are most affected while also being burdened with water collection issues. In several Nepalese public schools, the situation with regard to water, sanitation, and hygiene (WASH) is deplorable. According to Water Aid and the Department of Education (2014), only 69\% of Nepalese schools have separate toilets for girls, with approximately 166 girls sharing one toilet unit.

According to the Joint Monitoring Program (JMP) for water supply and sanitation conducted by the World Health Organization and the United Nations Children's Fund (WHO/UNICEF) in 2015, 663 million people lacked improved drinking water supplies and 2.4 billion lacked improved sanitation 
facilities. School sanitation and hygiene refers to a collection of hardware and software components that work together to create a healthy learning environment and encourage good hygiene habits. The complete kit of hardware in and around the school compound includes drinking water, hand washing, and sanitary facilities. The software consists of activities that encourage school conditions and practices that aid in the prevention of water-borne and sanitation-related diseases and parasites (UNICEF \& IRC 1998). Water, sanitation, and hygiene (WASH) facilities in schools have a significant impact on student enrollment, daily attendance, and retention, particularly among girls, and ultimately have an impact on the learning environment. It is also clear that inadequate WASH facilities and practices have an effect on student health and wellbeing. Water, sanitation, and washing facilities in schools, as well as hygiene education, are all part of the WASH in school concept. In the late 1980s, Nepal initiated a school sanitation and hygiene program. WASH sector initiatives, such as the Sanitation and Hygiene Master Plan of 2011 and the Total Sanitation Guidelines of 2017, have highlighted the importance of schools in instilling healthy hygiene and sanitation habits. Through a WASH sector development plan, the government of Nepal is committed to the Sustainable Development Goals (SDGs) for 2030, which aim to enhance universal access to water, sanitation, and hygiene for all people (NPC, 2017).

\section{NEED OF STUDY}

It has become clear that schools are crucial to achieving and maintaining the status of an opendefecation-free zone. WASH in the school profile will aid in the identification of significant deficiencies and obstacles in WASH results, as well as the development of tailored approaches. The profile is designed to assist schools in aligning their WASH standards with WASH sector policies. The profile is also intended to assist interested parties in implementing WASH measures in order to more effectively work against district sanitation goals.

\section{OBJECTIVES}

The study's goal was to recognize WASH gaps and needs in schools, which will help with policy development, program design, implementation, and evaluation. In specific, the study aimed to

- Identify availability and access of WASH facilities in schools

- Identify availability, access and Child, Gender and Disability (CGD) friendly status of WASH facilities in schools

- Assess hygiene education related inputs in schools and practices among school children

- Assess management, operation and maintenance of WASH in schools

- Analyze gaps and recommend necessary actions for WASH in school improvements

\section{MeTHODS}

From the survey's conception to its design, enumerator preparation, and data collection, it took a participatory approach. The survey used a qualitative census methodology since the aim of the status survey was to plan WASH in school status for all public schools. Data was collected using a validated questionnaire and observation checklist with parameters to verify availability, access, and behaviors from February to March 2018. The questionnaire was created with the study's goals in mind. In total, 3,534 public schools were reached through ten program districts: Rukum East, Rukum West, Jajarkot, Dailekh, Bajura, Achham, Doti, Dadeldhura, Baitadi, and Darchula. Every district's data questionnaires were collected and counted to ensure that all of the schools were covered. Before entering the data, all of the collected data was cleaned and coded. 
Water, Sanitation and Hygiene Condition in Public Schools from Ten Districts of Lumbini, Karnali and Sudurpaschim Province, Nepal

\section{STUDY DISTRICTS}

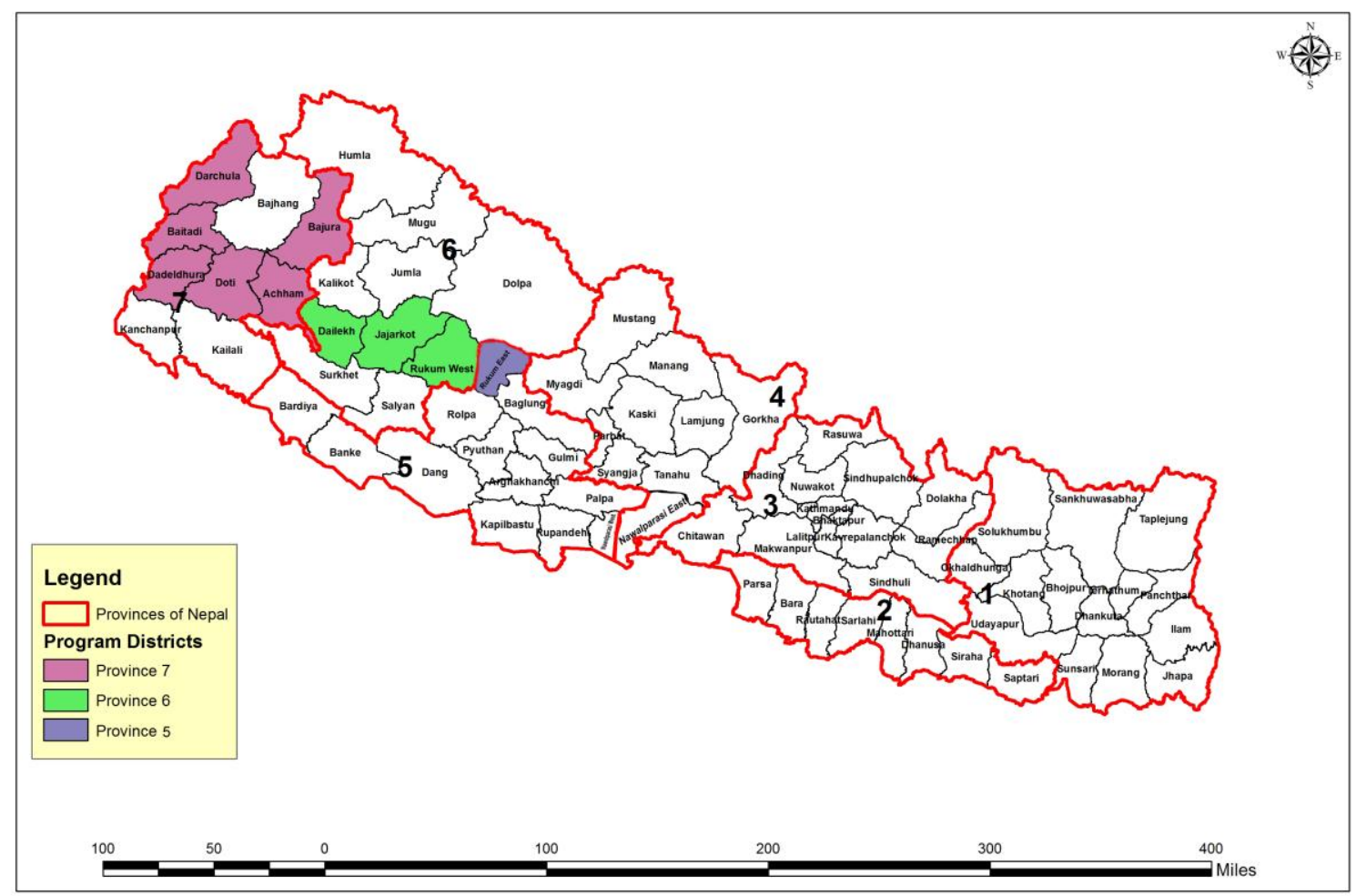

\section{RESULTS AND DISCUSSION}

The work was divided into sections to compare water supply, sanitation, and hygiene in public schools in the surveyed districts. There are 2,846 basic schools (80.5\%) and 688 secondary schools $(19.5 \%)$ in the public school system. Headmasters, School Teachers, WASH Focal Persons, and Others (school staffs, SMC, SWASHCC members) from public schools are among the respondents.

Table1. Availability of Water and Sanitation Facilities among Schools

\begin{tabular}{|c|c|c|c|}
\hline \multirow[t]{2}{*}{ Checklist } & \multicolumn{2}{|l|}{ Types of Schools } & \multirow[t]{2}{*}{ Total $(\%)$} \\
\hline & Basic Schools (\%) & Secondary Schools $(\%)$ & \\
\hline \multicolumn{4}{|c|}{ Availability of Water Supply Facilities in School } \\
\hline Yes & $1562(54.9)$ & $465(67.6)$ & $2027(57.4)$ \\
\hline No & $1284(45.1)$ & $223(32.4)$ & $1507(42.6)$ \\
\hline Total & $2846(100)$ & $688(100)$ & $3534(100)$ \\
\hline \multicolumn{4}{|c|}{ Availability of Sufficient Water } \\
\hline Yes & $1453(51.1)$ & $299(43.5)$ & $1752(49.6)$ \\
\hline No & $1393(48.9)$ & $389(56.5)$ & $1782(50.4)$ \\
\hline Total & $2846(100)$ & $688(100)$ & $3534(100)$ \\
\hline \multicolumn{4}{|c|}{ Water Storage Covered } \\
\hline Yes & $1658(58.3)$ & $471(68.5)$ & $2129(60.2)$ \\
\hline No & $1188(41.7)$ & $217(31.5)$ & $1405(39.8)$ \\
\hline Total & $2846(100)$ & $688(100)$ & $3534(100)$ \\
\hline \multicolumn{4}{|c|}{ Water Purification for Drinking } \\
\hline Yes & $461(16.2)$ & $132(19.2)$ & $593(16.8)$ \\
\hline No & $2385(83.8)$ & $556(80.8)$ & $2941(83.2)$ \\
\hline Total & $2846(100)$ & $688(100)$ & $3534(100)$ \\
\hline \multicolumn{4}{|c|}{ Availability of Toilet Facilities } \\
\hline Yes & $2667(93.7)$ & $678(98.5)$ & $3345(94.7)$ \\
\hline No & $179(6.3)$ & $10(1.5)$ & $189(5.3)$ \\
\hline Total & $2846(100)$ & $688(100)$ & $3534(100)$ \\
\hline \multicolumn{4}{|c|}{ Availability of Separate Toilet for Male and Female Students } \\
\hline Yes & $1382(51.8)$ & $530(78.2)$ & $1912(57.2)$ \\
\hline No & $1285(48.2)$ & $148(21.8)$ & $1433(42.8)$ \\
\hline
\end{tabular}


Water, Sanitation and Hygiene Condition in Public Schools from Ten Districts of Lumbini, Karnali and Sudurpaschim Province, Nepal

\begin{tabular}{|l|l|l|l|}
\hline Total & $2667(100)$ & $678(100)$ & $3345(100)$ \\
\hline Availability of Urinals & $933(32.8)$ & $361(52.5)$ & $1294(36.6)$ \\
\hline Yes & $1913(67.2)$ & $327(47.5)$ & $2240(63.4)$ \\
\hline No & $2846(100)$ & $688(100)$ & $3534(100)$ \\
\hline Total & $557(59.7)$ & $262(72.6)$ & $819(63.3)$ \\
\hline Separate Urinal Units for Girls and Boys & $99(27.4)$ & $475(36.7)$ \\
\hline Yes & $376(40.3)$ & $361(100)$ & $1294(100)$ \\
\hline No & $933(100)$ & & $2341(66.2)$ \\
\hline Total & $1931(67.8)$ & $278(40.4)$ & $1193(33.8)$ \\
\hline Availability of Hand washing Facilities & $688(100)$ & $3534(100)$ \\
\hline Yes & $915(32.2)$ & & $1061(30)$ \\
\hline No & $2846(100)$ & $278(40.4)$ & $2473(70)$ \\
\hline Total & $410(59.6)$ & $3534(100)$ \\
\hline Provision of Operation and Maintenance & $688(100)$ & (5) \\
\hline Yes & $783(27.5)$ & & \\
\hline No & $2063(72.5)$ & & \\
\hline Total & $2846(100)$ & & \\
\hline
\end{tabular}

Table 1 shows that just 57.4 percent of schools have water storage systems on site. Secondary schools had a marginally higher proportion $(67.6 \%)$ than basic schools (54.9\%). Despite the availability of water sources, many schools also lack basic water supplies. Any school with a water source has enough water for the students and teachers. Water purification and use is a relatively uncommon procedure in rural areas. Just $16.8 \%$ of the schools were found to use purification methods for drinking purposes. Among the schools practicing water purification, filtration using water filter was most common method found $(75.5 \%)$ followed by boiling $(9.9 \%)$, chlorination (6\%) and SODIS $(5.4 \%)$.

At least one toilet is available in over $90 \%$ of schools. Still, 5\% of schools, including secondary schools, do not have toilets (1.5\%). In schools without toilet facilities, students and teachers have no choice but to defecate and urinate in the open. Just $57.2 \%$ of schools with toilets had separate male and female toilet facilities, according to the study. In secondary schools, the proportion was marginally higher (78.2\%). Just $36.6 \%$ of schools have toilets with urinals. A urinal facility is available in half of secondary schools (52.5\%). Separate urinals for boys and girls are also used in $63.3 \%$ of such colleges.

In total, $66.2 \%$ of schools replied that hand washing facilities were available. The majority of schools $(73.9 \%)$ with hand washing facilities use very simple facilities such as a bucket and mug. Just $18.6 \%$ of schools have tippy taps or child-friendly taps with or without basin. The availability of operation and maintenance (O\&M) funds has been observed in $30 \%$ of schools. Last year, 30.6\% of schools were found to have maintained WASH-related facilities. However, $92.3 \%$ of schools reported having a system in place to clean school grounds and buildings, which was run by school support staff, students, and members of the child club.

Table2. Practices of the Students on Water, Sanitation and Hygiene

\begin{tabular}{|l|l|l|l|}
\hline \multirow{2}{*}{ Checklist } & Types of Schools & \multirow{2}{*}{ Total (\%) } \\
\cline { 2 - 3 } & Basic Schools (\%) & Secondary Schools (\%) & \\
\hline Students wash their hands with soap after toilet & $169(41.2)$ & $503(21.5)$ \\
\hline Wash with water only & $334(17.3)$ & $204(49.8)$ & $1725(73.7)$ \\
\hline Wash with water and soap & $1521(78.8)$ & $10(2.4)$ & $20(0.8)$ \\
\hline Wash with other materials & $10(0.5)$ & $27(6.6)$ & $93(4)$ \\
\hline Do not wash & $66(3.4)$ & $410(100)$ & $2341(100)$ \\
\hline Total & $1931(100)$ & $151(36.8)$ & $476(20.3)$ \\
\hline Students wash their hands with soap before meal & $136(33.2)$ & $1566(66.9)$ \\
\hline Wash with water only & $325(16.8)$ & $4(1)$ & $12(0.5)$ \\
\hline Wash with water and soap & $1430(74.1)$ & $119(29)$ & $287(12.3)$ \\
\hline Wash with other materials & $8(0.4)$ & $410(100)$ & $2341(100)$ \\
\hline Do not wash & $168(8.7)$ & & \\
\hline \multicolumn{2}{|l|}{ Total } & $1931(100)$ & \\
\hline Hygiene Education in all classes & & \\
\hline
\end{tabular}


Water, Sanitation and Hygiene Condition in Public Schools from Ten Districts of Lumbini, Karnali and Sudurpaschim Province, Nepal

\begin{tabular}{|l|l|l|l|}
\hline Yes & $1791(62.9)$ & $473(68.7)$ & $2264(64.1)$ \\
\hline No & $1055(37.1)$ & $215(31.3)$ & $1270(35.9)$ \\
\hline Total & $2846(100)$ & $688(100)$ & $3534(100)$ \\
\hline Classes on Menstrual Hygiene Management from class six & $389(56.5)$ & $808(22.9)$ \\
\hline Yes & $419(14.7)$ & $299(43.5)$ & $2726(77.1)$ \\
\hline No & $2427(85.3)$ & $688(100)$ & $3534(100)$ \\
\hline Total & $2846(100)$ & $111(16.1)$ & $255(7.2)$ \\
\hline Training and Use of Sanitary Pads & $144(5.1)$ & $577(83.9)$ & $3279(92.8)$ \\
\hline Yes & $2702(94.9)$ & $688(100)$ & $3534(100)$ \\
\hline No & $2846(100)$ &
\end{tabular}

Soap was found near hand washing stations or water facilities in the majority of the schools $(77.7 \%)$. The schools were also questioned about soap supply on a daily basis and throughout the year. The availability of soap during the year was stated by $66.1 \%$ of schools. The practice of community hand washing has been evaluated based on Table 2. Overall, $96 \%$ of schools reported that students wash their hands after using the toilet, either with water, water and soap, or other products. After using the toilet, $73.7 \%$ of schools reported that students wash their hands with soap and water. The use remarkably lower among secondary students $(49.8 \%)$ compare to basic schools $(78.8 \%)$. Similarly, $87.7 \%$ schools students wash their hand before meals. Just $66.9 \%$ of schools reported that students wash their hands with soap and water before eating. As compared to basic schools $(74.1 \%)$, the proportion of secondary school students $(33.2 \%)$ is slightly lower. The survey looked at health and hygiene education/promotional practices, as well as menstrual hygiene education, training, and sanitary pad use. Just $64.1 \%$ of schools teach hygiene education unless it is already part of the curriculum. Similarly, $22.9 \%$ of schools manage courses on menstrual hygiene management beginning in sixth grade, with the exception of content covered in the curriculum. Just $7.2 \%$ of schools have been educated on how to make and use sanitary pads.

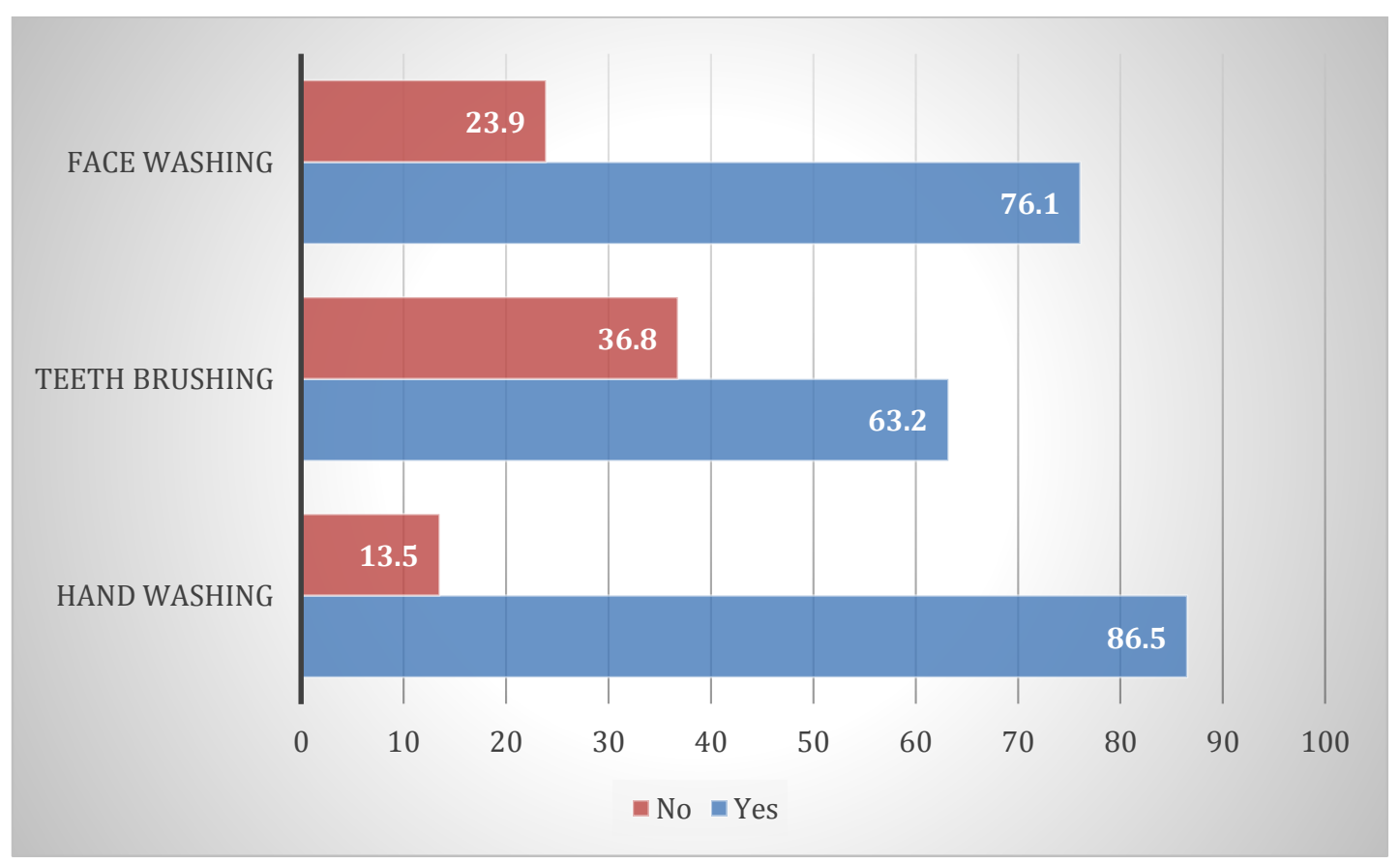

Figure1. Group Sanitation Practices in the Schools

Handwashing in groups is successful at preventing disease transmission and offers an environment in which many students can wash their hands at the same time. These techniques give students enough time to properly wash their hands without having to hurry because of a long line of other students. It also makes it simple for teachers to track students' hand-washing habits and encourage them to use proper hand-washing techniques. Hand washing in groups is an enjoyable activity that allows students to wash their hands properly. $86.5 \%$ of schools reported that their students practiced group hand washing with soap and water. However, the survey found slightly lesser proportion of schools where students practices teeth brushing $63.2 \%$ and face washing $76.1 \%$. 
Water, Sanitation and Hygiene Condition in Public Schools from Ten Districts of Lumbini, Karnali and Sudurpaschim Province, Nepal

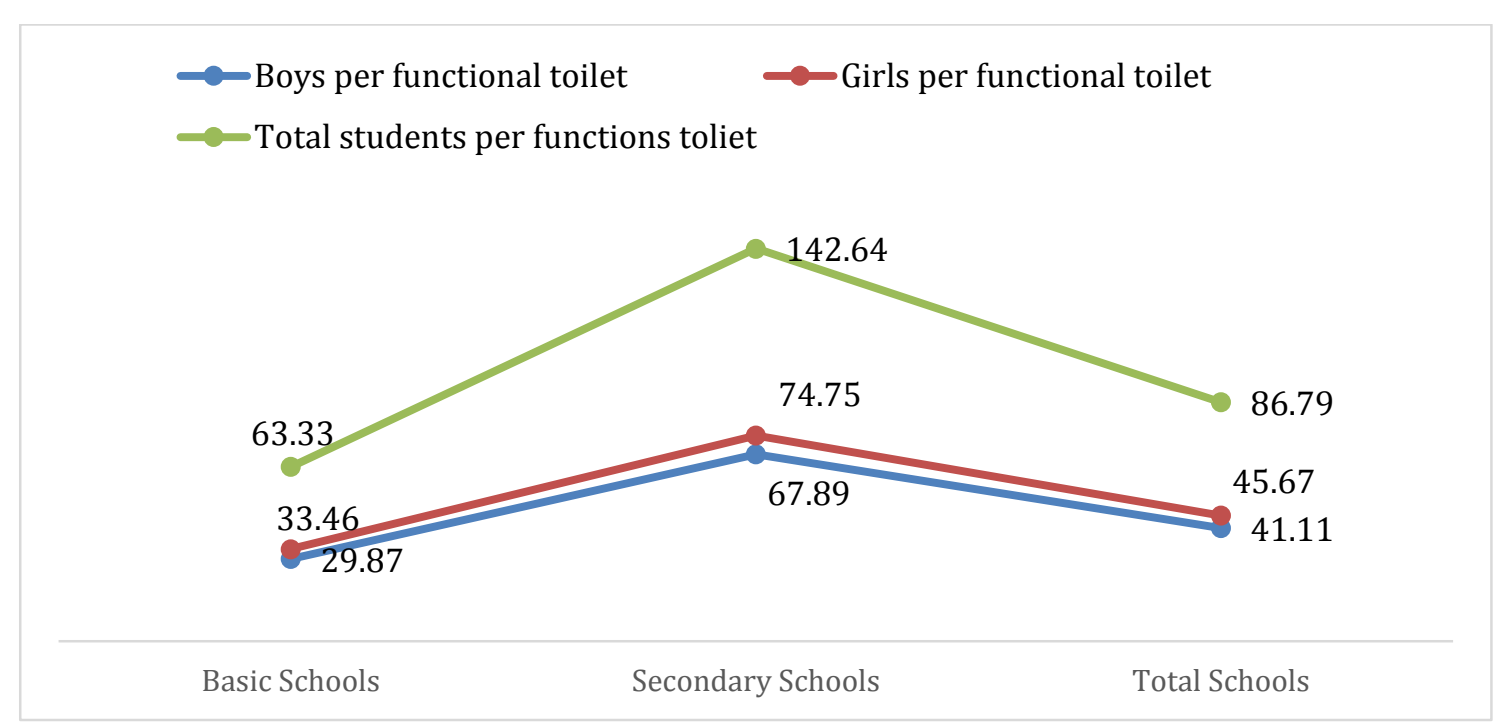

Figure2. Students per Functional Toilet Unit in Ratio

At least one toilet is available in over $90 \%$ of schools. Almost all of the toilets were found to be operational and in service. The status of cleanliness, water supply, and privacy, on the other hand, varied greatly. According to the report, $15.4 \%$ of these units were not working. The toilet-to-student ratio was also taken into consideration. According to the findings, there is one usable toilet unit for every 87 students. This ratio is higher than the government's minimum standard of one toilet unit per 50 students, indicating that more toilet units are required.

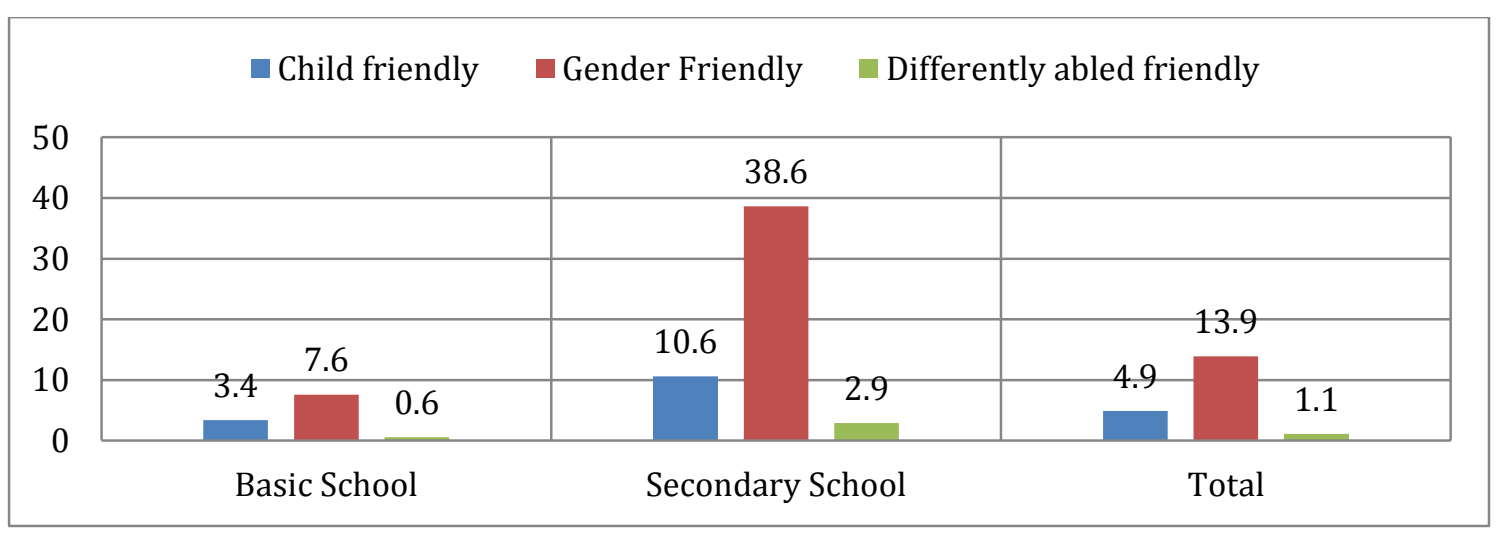

Figure3. CGD Friendly Toilet in \%

All toilets were inspected using eight standard criteria for child-friendly status, three standard criteria for gender-friendly status, and five standard criteria for differently-abled friendly toilet to assess CGD friendly toilet. Just 163 toilets (91 basic schools and 72 secondary schools) met the child-friendly requirement for toilets in schools, according to the composition index based on eight criteria. Just 464 toilets (202 basic and 262 secondary schools) are equipped with girl-friendly features. Similarly, among the usable toilets in the surveyed school shown in figure 3, 36 toilets (16 basic school and 20 secondary school) are differently-abled friendly toilets.

Table3. Waste Collection and Disposal in Schools

\begin{tabular}{|l|l|l|l|}
\hline \multirow{2}{*}{ Checklist } & \multicolumn{2}{|l|}{ Types of Schools } & Total (\%) \\
\cline { 2 - 4 } & Basic Schools (\%) & Secondary Schools (\%) & $2641(74.7)$ \\
\hline $\begin{array}{l}\text { Structure for collection of } \\
\text { solid waste }\end{array}$ & $2154(75.5)$ & $487(70.8)$ & $850(24.1)$ \\
\hline $\begin{array}{l}\text { Provision for separate } \\
\text { bins in school compound }\end{array}$ & $698(24.5)$ & $152(22.1)$ & $3173(89.8)$ \\
\hline Waste disposed weekly & $2563(90.1)$ & $610(88.7)$ & $2996(84.8)$ \\
\hline Garbage pit provision & $2432(85.5)$ & $564(82.0)$ & $568(16.1)$ \\
\hline $\begin{array}{l}\text { Waste water management } \\
\text { provision }\end{array}$ & $444(15.6)$ & $124(18.0)$ & \\
\hline
\end{tabular}


Water, Sanitation and Hygiene Condition in Public Schools from Ten Districts of Lumbini, Karnali and Sudurpaschim Province, Nepal

\begin{tabular}{|l|l|l|l|}
\hline $\begin{array}{l}\text { Availability of dust bins } \\
\text { in every class }\end{array}$ & $1327(46.6)$ & $324(47.1)$ & $1651(46.7)$ \\
\hline
\end{tabular}

Waste management was evaluated beginning with the collection of waste from classrooms and school grounds, as well as the location and timing of its disposal. Waste-water drainage and control were also included in the evaluation. All of the school respondents were asked if waste disposal buckets or bins were available on school grounds. It was discovered that $74.7 \%$ of schools have such a facility. Just $24.1 \%$ of schools have separate bins for degradable and non-degradable waste collection. It was discovered that $84.8 \%$ of schools had a garbage pit. Similarly, only $16.1 \%$ of schools have a wastewater treatment system in place. It was also discovered that fewer than half of the schools $(46.7 \%)$ have dust bins in the classroom. $62.3 \%$ of schools bury or burn collected waste on premises, while $31.3 \%$ of schools dump collected solid waste on school premises. In terms of routine management, it was discovered that $89.8 \%$ of the schools surveyed dispose of their waste regularly.

\section{CONCLUSiONS}

The WASH in School profile outlined a range of areas where priority and focus are needed to improve the water, hygiene, and sanitation status of schools, as envisioned by the national WASH in School Operational Procedure, 2074, the school sector development plan, and the child national framework for child friendly schools. The survey offers an evidence-based understanding of the state of WASH in public schools, which will serve as a valuable guide for stakeholders at the provincial, district, and, most critically, local levels as they focus on WASH in school programs and their links to national sanitation goals. The main conclusions of the WASH Profile of public schools are as follows:

$>\quad$ Public schools in mid and far western region continue to face the lack of water facility and sufficiency. Nearly half of the schools lack water facility supply within the school premises and adequate water

$>\quad$ Majority of schools uses not treated water for drinking purposes. Only $16.8 \%$ of schools practices water purification

$>\quad \mathrm{Al}$ least one toilet facility is available in majority of the schools (94.6\%), but only $57.2 \%$ public schools have separate toilet for boys and girls. In an average there is one toilet unit for every 87 students, which is above national standard (1:50)

$>\quad$ Availability of urinal facility is minimal in public schools. Only $36 \%$ of the schools had urinal facilities. Student urinal unit ration was even high ie, 1:287

$>\quad$ Lesser number of schools had child friendly toilet (4.8\%). Likewise girl's friendly toilets were found in $13.9 \%$ of the schools. Only $1.1 \%$ of the schools had toilets accessible to disable students

$>\quad$ Menstrual hygiene management facilities are available in $11.6 \%$ of public schools. The proportion is less in basic school, $6.8 \%$ only

$>\quad$ Majority of the schools have structures for waste collection within school premises

$>\quad$ Less than on-fourth schools have hand washing facilities with tippy taps or child friendly taps

$>\quad$ Hand washing behaviors with soap and water was relatively improving. However about onefourth of the student still uses water only for hand washing

$>\quad$ Education and awareness on menstrual hygiene and management is relatively low

RECOMMENDATION

For evidence-based planning, sustainability and scaling up of WASH in school Program

$>\quad$ Need to upgraded gradually in line with the spirit, target and indicators of total sanitation campaign and sustainable development goal target

Persuasion of local government, cross-sector collaboration, dissemination of technical manuals, conduction of capacity development activities, establishment of accountability, reward and penalty mechanism and knowledge management seems essential 
$>\quad$ Creative engagement of child clubs and SWASHCC in planning and self monitoring, installation of low cost water purification technologies in schools, close monitoring of hand washing with soap

$>\quad$ Increase awareness through Child-friendly behavior change communication to improve practice

$>$ Increase access to hardware component to address needs across all public schools irrespective of school type

Promote water purification practice introducing feasible water purification methods to ensure safe and clean drinking water for students is available on a regular basis

$>\quad$ Increase awareness through child-friendly behavior change communication to improve practice

$>\quad$ Introduce and implement School WASH Operational Guideline in close coordination with and support from local government

\section{ACKNOWLEDGEMENT}

McGovern-Dole International Food for Education and Child Nutrition Program of United States Department of Agriculture financially supported this research work. The authors are thankful to Integrated Development Society-Nepal (IDS-Nepal) for the data and World Food Programme (WFP) to conduct research work smoothly and to all other research partners for making the study results accessible to the authors.

\section{REFERENCES}

[1] GoN, Center for Education and Human Resource Development; 2019. School WASH Operational Guidelines 2074, $2^{\text {nd }}$ Amendment

[2] GoN, DoE \& WFP-Nepal; 2016. Water, Sanitation and Hygiene (WASH) Profile of Public Schools in Bajhang

[3] GoN, Ministry of Water Supply and Sanitation; 2017. Total Sanitation Guidelines

[4] GoN, Steering Committee for National sanitation Action; 2011. Sanitation and Hygiene Master Plan

[5] National Planning Commission; 2017. Nepal's Sustainable Development Goals, Baseline Report, 2017. Government of Nepal, National Planning Commission, Nepal

[6] United Nations Children's Fund (UNICEF) and IRC, International Water and Sanitation Centre; 1998. A Manual on School Sanitation and Hygiene

[7] Water Aid \& Department of Education (DoE); 2014. WASH Financing in Community Schools of Nepal

[8] WFP-Nepal \& IDS-Nepal; 2019. Water, Sanitation and Hygiene (WASH) Profile of Public Schools in selected Ten Districts of Province 5, 6 \& 7

[9] World Health Organization (WHO); 2004. Water, Sanitation and Hygiene Links to Health, Facts and Figures

[10] World Health Organization \&United Nations Children's Fund; 2015. Progress on Sanitation and Drinking Water: 2015 Update and MDG Assessment; World Health Organization, Switzerland

Citation: Mr. Anjan Kumar Phoju,et.al., "Water, Sanitation and Hygiene Condition in Public Schools from Ten Districts of Lumbini, Karnali and Sudurpaschim Province, Nepal.", International Journal of Research in Environmental Science (IJRES), vol. 7, no. 2, pp. 36-43, 2021. Available: DOI: http://dx.doi.org/ 10.20431/2454-9444.0702004

Copyright: () 2021 Authors. This is an open-access article distributed under the terms of the Creative Commons Attribution License, which permits unrestricted use, distribution, and reproduction in any medium, provided the original author and source are credited. 